\title{
Improving corrosion performance by surface patterning
}

\author{
M. Bigdeli Karimi, V. Stoilov \& D. O. Northwood \\ University of Windsor, Canada
}

\begin{abstract}
Based on the idea that hydrophobic (low or non-wettable) surfaces can decrease the contact area between a corrosive solution and a surface, thereby potentially rendering the material more corrosion resistant, the effect of surface patterning on the corrosion behaviour of nickel was investigated. The surface patterning consisted of an array of holes of various diameters (D) and inter-hole spacings (L) that were produced by a laser ablation process. The corrosion behaviour of the patterned surfaces was studied using a potentiodynamic polarization method in a $0.5 \mathrm{M} \mathrm{H}_{2} \mathrm{SO}_{4}$ electrolyte and compared with that of a polished reference sample. Following the potentiodynamic polarization corrosion test cycle, the corroded surfaces were examined using scanning electron microscopy (SEM) for morphological features and white light interferometry (WLI) to determine the surface roughness. The changes in surface morphology were related to the corrosion behaviour. A relationship was found between $\mathrm{D}, \mathrm{L}$ and the corrosion current density $\left(I_{\text {corr }}\right)$, whereby the higher the $(\mathrm{D} / \mathrm{L})^{2}$ ratio, the higher the $I_{\text {corr }}$ value. The corrosion potential $\left(E_{\text {corr }}\right)$ of all surface patterned samples was lower (less noble) than that of the reference sample in all tests.

Keywords: corrosion resistance, surface patterning, hydrophobicity, laser ablation.
\end{abstract}

\section{Introduction}

Wettability of solid surfaces is an important property and depends both on the surface chemistry and on the surface topology. Recently, hydrophobic and superhydrophobic surfaces (water contact angles larger than $150^{\circ}$ ) have received a lot of attention, due to their important applications ranging from self-cleaning materials and in-flight icephobic treatment [1] to microfluidic devices. The 
archetype superhydrophobic surface is that of the lotus leaf, on which a water droplet apparently forms a sphere, reducing the area of contact. This behavior, known as the lotus-leaf-effect, is found to be a result of the hierarchically patterned structure. Effectively the fluid cannot penetrate the air gaps between the patterned pillars on the surface, and therefore it forms a heterogeneously wetted contact surface of alternating liquid/solid contacts and air pockets. As a result the overall solid liquid contact area is significantly reduced [2-5].

In the present work, surface patterning is employed to create heterogeneous wetting on metallic surfaces. It is shown that heterogamous wetting in metallic surfaces leads to reduction in corrosion rates and increase in corrosion resistance.

\section{Experimental procedures}

\subsection{Specimen preparation}

Pure nickel (99.7 Wt.\%) was selected as a model metal. Samples of $1.5 \mathrm{~cm} \times$ $1.5 \mathrm{~cm}$ size were polished to a standard finish with a roughness that did not exceed $50 \mathrm{~nm}$. Laser ablation with a single pulse copper bromide $(\mathrm{CuBr})$ metal vapour laser was used to create special surface textures. During laser ablation, nitrogen $\left(\mathrm{N}_{2}\right)$ was blown to protect the surfaces from oxidation and clean any debris. The pulse duration was selected at $30 \mathrm{~ns}$. Different hole/pattern sizes were achieved with different laser output power within the range of 20-80 W. Fig. 1 shows a schematic of the applied pattern. The diameter of the holes and the inter-hole spacing were varied to obtain different textures. Table 1 presents the selected hole size and the inter-hole spacing. The distances between the holes are labeled L1, L2 and L3, where as the D1, D2, D3 etc are the hole diameters.

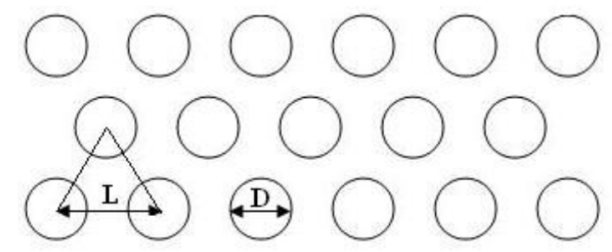

Figure 1: Schematic presentation of the proposed surface texture; D relates to the hole diameter and $\mathrm{L}$ defines the inter-hole spacing.

Table 1: The hole sizes and inter-hole spacing.

\begin{tabular}{|c|c|c|c|}
\hline $\begin{array}{c}\text { Hole diameter } \\
\text { (D) } \boldsymbol{\mu \mathbf { m }}\end{array}$ & $\begin{array}{c}\text { Inter-hole spacing } \\
\mathbf{L}_{\mathbf{1}}, \boldsymbol{\mu \mathbf { m }}\end{array}$ & $\begin{array}{c}\text { Inter-hole spacing } \\
\mathbf{L}_{2}, \boldsymbol{\mu} \mathbf{m}\end{array}$ & $\begin{array}{c}\text { Inter-hole } \\
\text { spacing } \\
\mathbf{L}_{3}, \boldsymbol{\mu} \mathbf{m}\end{array}$ \\
\hline 5 & 5 & 10 & 20 \\
\hline 10 & 10 & 20 & 30 \\
\hline 20 & 20 & 30 & 40 \\
\hline
\end{tabular}


For easy identification of the samples, the following sample labeling system has been adopted: DxLy, where $\mathrm{x}$ is the diameter of the hole in $\mu \mathrm{m}$ and the $\mathrm{y}$ is the inter-hole spacing in $\mu \mathrm{m}$.

\subsection{Corrosion tests}

The corrosion resistance of the samples was determined using a potentiodynamic polarization corrosion test, wherein the samples were immersed into a $0.5 \mathrm{M} \mathrm{H}_{2} \mathrm{SO}_{4}$ solution at room temperature $\left(24^{\circ} \mathrm{C}\right)$. A conventional three-electrode system was used in which a standard calomel electrode (SCE) served as the reference electrode and a platinum electrode as a cathode electrode. In the tests, the applied potentials were in the range of -0.7 to $1.5 \mathrm{~V}$ (with respect to SCE) with a scan rate of $1.0 \mathrm{mV} / \mathrm{s}$. Corrosion rates were calculated in terms of the corrosion current density, $I_{\text {corr }}$, by using linear polarization resistance (LPR) curves. The relationship between $I_{c o r r}$ and the polarization resistance, $R_{p}$, is obtained from the Stearn-Geary equation [6]:

$$
R_{p}=\frac{\Delta E}{\Delta i_{\text {app }}}=\frac{\beta_{a} \beta_{c}}{2.3 I_{\text {corr }}\left(\beta_{a}+\beta_{c}\right)}
$$

where $\beta_{a}$ and $\beta_{c}$ are the Tafel slopes of the anodic and cathodic reactions, respectively, $I_{\text {corr }}$ is the corrosion current density and the ratio $\left(\Delta E / \Delta i_{\text {app }}\right)$ is the polarization resistance. After the corrosion test, the sample surfaces were examined using JEOL 5800 scanning electron microscopy (SEM), and energydispersive X-ray spectrometry (EDS).

\section{Results and discussion}

\subsection{Corrosion tests}

The electrochemical characteristics of the patterned $\mathrm{Ni}$ samples were investigated by potentiodynamic techniques described in section 2.2. Polarization curves for all patterned samples and the reference sample were analyzed and the corresponding corrosion current density, $I_{\text {corr }}$, and potential, $E_{\text {corr }}$, were obtained. Fig. 2 shows the variation of the $I_{\text {corr }}$ for different hole diameters (1/D) in samples with the same ratio of patterned to non-patterned area $(\mathrm{D} / \mathrm{L})^{2}$. Clearly samples with $\mathrm{D}=10 \mu \mathrm{m}\left(1 / \mathrm{D}=0.1 \mu \mathrm{m}^{-1}\right)$ have the worst corrosion properties compared to any other samples with other pattern density, that is, $(\mathrm{D} / \mathrm{L})^{2}=0.25$ and $(\mathrm{D} / \mathrm{L})^{2}=1.0$. On the other hand, samples with $\mathrm{D}=20 \mu \mathrm{m}\left(1 / \mathrm{D}=0.05 \mu \mathrm{m}^{-1}\right)$ show the lowest $I_{\text {corr }}$, and therefore better corrosion resistance at either pattern density. In addition, the corrosion resistance observed in samples with $\mathrm{D}=20 \mu \mathrm{m}$ exceeds the performance of the reference sample $\left(1 / \mathrm{D}=0.0 \mu \mathrm{m}^{-1}\right)$, which is a significant improvement of the corrosion properties of the metal surface. The observed trends in Fig. 2 suggest that a decrease of the hole size (D) $\mu \mathrm{m}$ towards nano-scale size could decrease the corrosion current density, $I_{\text {corr }}$, even further. Fig. 3 presents the $E_{\text {corr }}$ values for samples with a pattern density of $(\mathrm{D} / \mathrm{L})^{2}=1$ and $(\mathrm{D} / \mathrm{L})^{2}=0.25$. The corrosion potential $\left(E_{\text {corr }}\right)$ of all surface patterned samples was lower (less noble) than that of the reference sample $\left(1 / \mathrm{D}=0.0 \mu \mathrm{m}^{-1}\right)$ in all tests. 


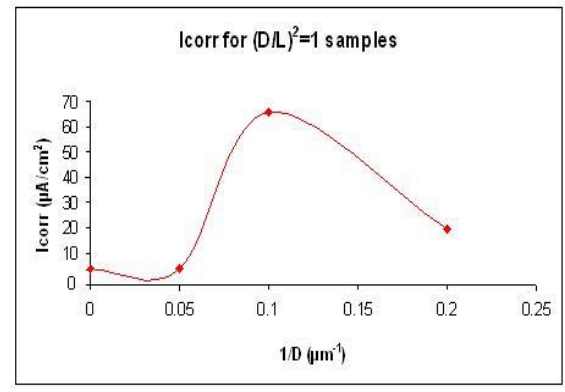

(a)

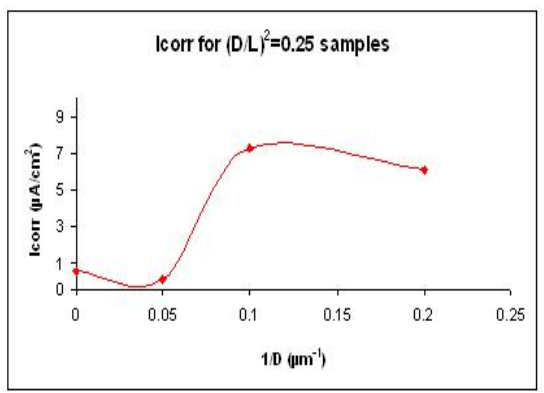

(b)

Figure 2: $\quad I_{\text {corr }}$ values versus inverse hole diameters (1/D) for all samples with $(\mathrm{D} / \mathrm{L})^{2}=1$ and $(\mathrm{D} / \mathrm{L})^{2}=0.25$ after the corrosion test.

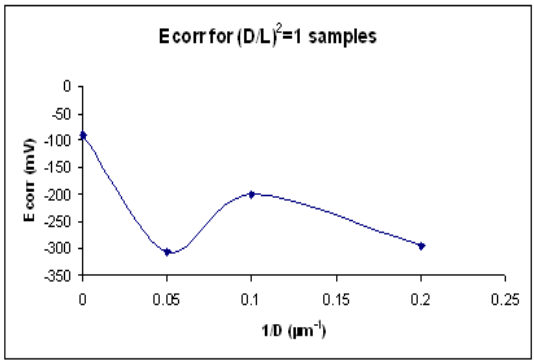

(a)

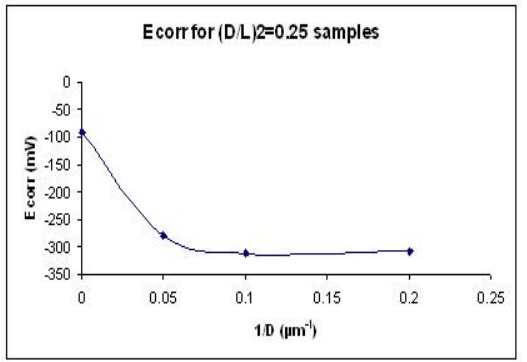

(b)

Figure 3: $\quad E_{\text {corr }}$ values versus inverse hole diameters (1/D) for all samples with $(\mathrm{D} / \mathrm{L})^{2}=1$ and $(\mathrm{D} / \mathrm{L})^{2}=0.25$ after the corrosion test.

\subsection{SEM images after corrosion tests}

The patterned samples were examined by SEM before and after the above corrosion tests (see Figs. 4-6). The original REF sample showed some severe, localized corrosion. It is evident that those areas were formed by coalescence of small pits.

Sample D10L30 had a severely corroded appearance (Figs. 5a and 5b). According to $I_{\text {corr }}$ of this sample, there is a good agreement between corrosion current density and the surface condition.

Sample D20L40 exhibited the lowest amount of patterning degradation. Comparing the original sample before and after the corrosion test there was no obvious change of the surface pattern (Figs. 6(a) and 6(b)). The measured $I_{\text {corr }}$ for this sample was the lowest of all samples including reference and patterned. No surface damaged was detected also in samples D20L20 and D20L40. Clearly the observed surface damage in all samples was in good agreement with the trends predicted by the measured $I_{\text {corr }}$ values. 


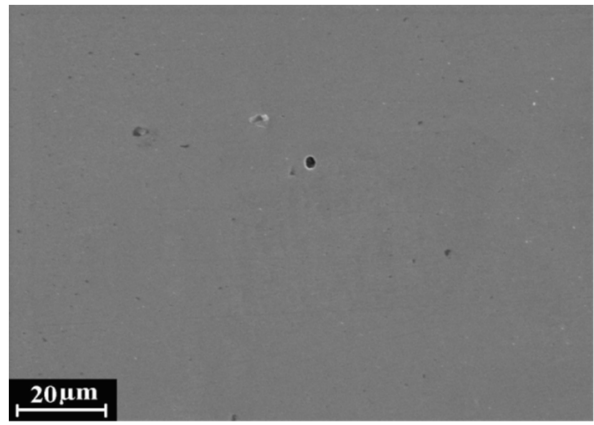

(a)

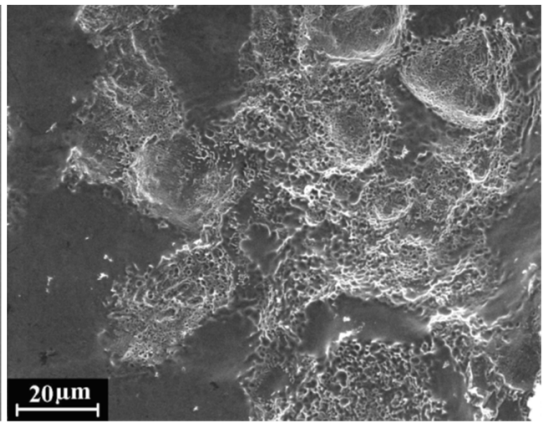

(b)

Figure 4: $\quad$ SEM images of the reference sample (REF) (a) before and (b) after corrosion testing.

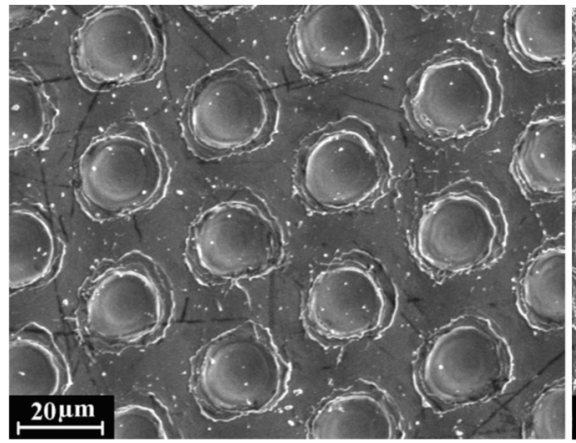

(a)

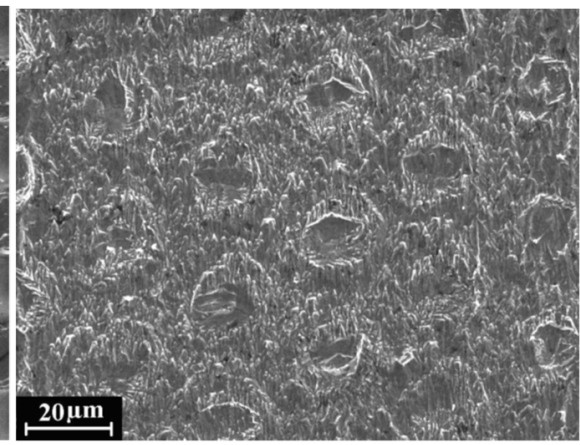

(b)

Figure 5: SEM images of the D10L30 (a) before and (b) after corrosion testing.

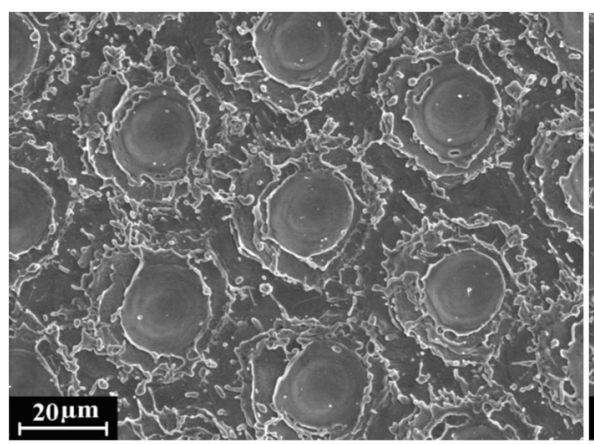

(a)

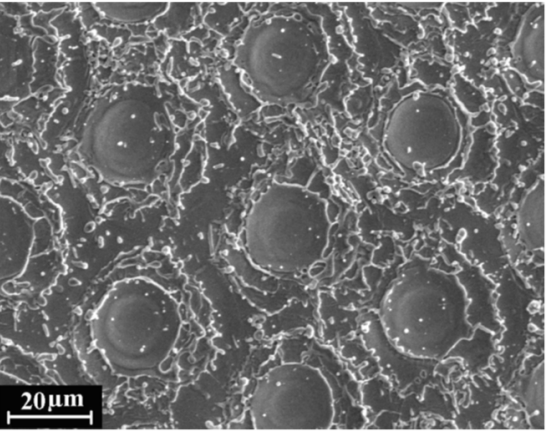

(b)

Figure 6: SEM images of the D20L40 (a) before and (b) after corrosion testing. 


\subsection{EDS analysis of the patterned samples}

In order to investigate the significant improvement of the corrosion resistance in some samples, energy-dispersive X-ray spectrometry (EDS) was used. The main goal was to evaluate the change of the $\mathrm{O}$ concentration on the surface of the samples and on the inside of the patterned holes. Fig. 7(a) refers to sample REF before the corrosion test. In the spectrum, three elements, nickel (Ni), oxygen $(\mathrm{O})$ and carbon $(\mathrm{C})$ are observed. The intensity of the most intense peaks $\left(\mathrm{Ni}: \mathrm{L}_{\alpha}=0.851\right.$ and $\mathrm{O}: \mathrm{K}_{\alpha}=0.523 \mathrm{keV}$ ) was used to calculate the ratio of $\mathrm{Ni} / \mathrm{O}$ (see Fig. 7(a)).

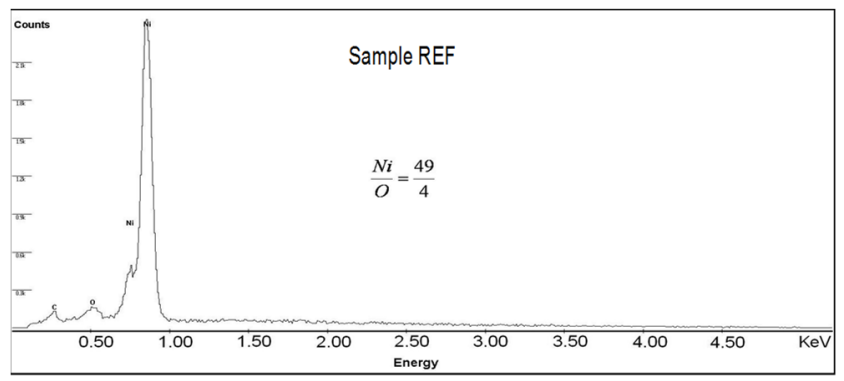

(a)

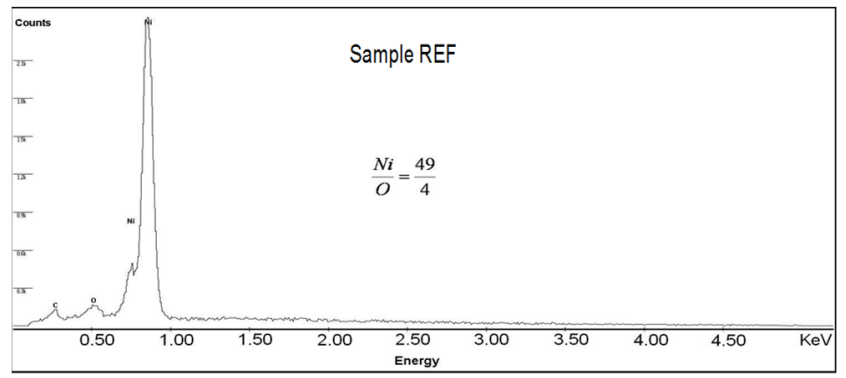

(b)

Figure 7: EDS analysis of the reference sample REF (a) before and (b) after corrosion testing.

Comparing sample REF before the test (Fig. 7(a)) and after the test (Fig. 7(b)) shows that there is virtually no change in the $\mathrm{O}$ concentration on the surface. The $\mathrm{Ni} / \mathrm{O}$ ratio remained at 49/5, indicating that a passive oxide layer was not formed. Similar EDS spectra were obtained for all corrosion damaged samples. For instance, the EDS spectra of sample D5L20 on the surface (Fig. 8(a)) and in the hole (Fig. 8(b)) after corrosion testing do not show any significant difference and the $\mathrm{Ni} / \mathrm{O}$ ratio is the same as for the polished REF sample. However, the EDS spectra for the patterned samples with the improved corrosion properties (D20L20, D20L30, and D20L40) exhibit different behaviour. The $\mathrm{Ni} / \mathrm{O}$ ratios for sample D20L40 before and after the corrosion test are shown in Figs. 9(a), 9(b) and 
Figs. 10(a), 10(b). The concentration of the $\mathrm{O}$ on the surface before and after the corrosion test slightly changed, which is consistent with the other corrosion damaged samples.

However, the bottom of the patterned holes shows significant increase in O concentration (Figs. 8(b) and 10(b)). This clearly indicates that Ni oxides were formed but were not dissolved by the electrolyte. A possible explanation could be that the fluid did not actually reach the bottom of the patterned hole. In other words, in the samples with better corrosion resistance, the contact between the electrolyte and the metal surface is heterogeneous wetting - alternating solid/liquid zones and air pockets.

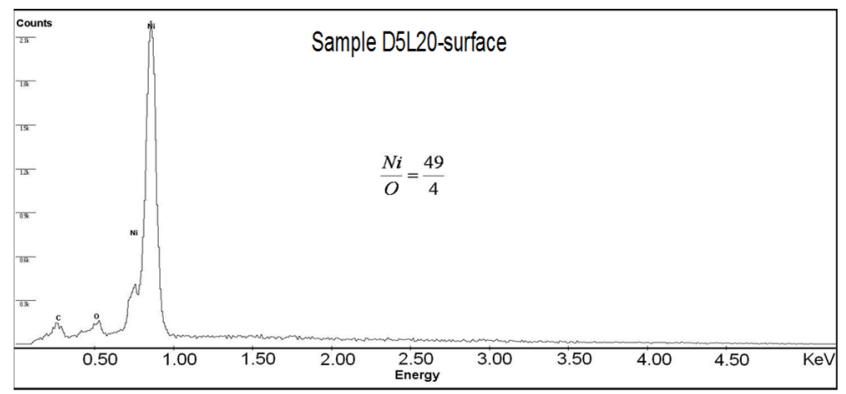

(a)

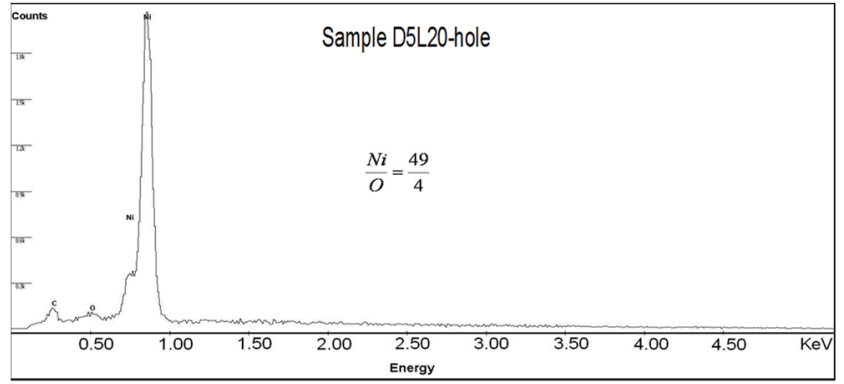

(b)

Figure 8: EDS analysis of the sample D5L20 after the corrosion test (a) surface and (b) hole.

\section{Conclusions}

Surface patterns with different pattern density were successfully created on Ni by laser ablation. The patterns had a distinct effect on the corrosion properties of the metallic surfaces. A specific group of patterns led to significant decrease of the corrosion current density and the corresponding corrosion rate. For this group of patterns, it has been shown that a possible reason for the decrease in corrosion rate is the detected heterogeneous wetting on the patterned surface. 
180 Corrosion: Material Performance and Cathodic Protection

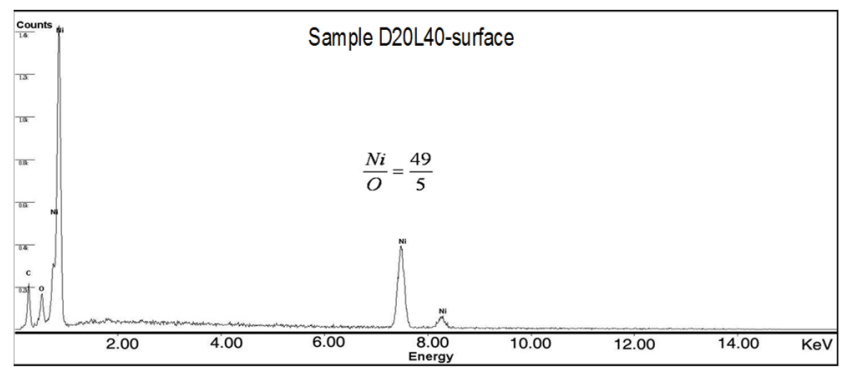

(a)

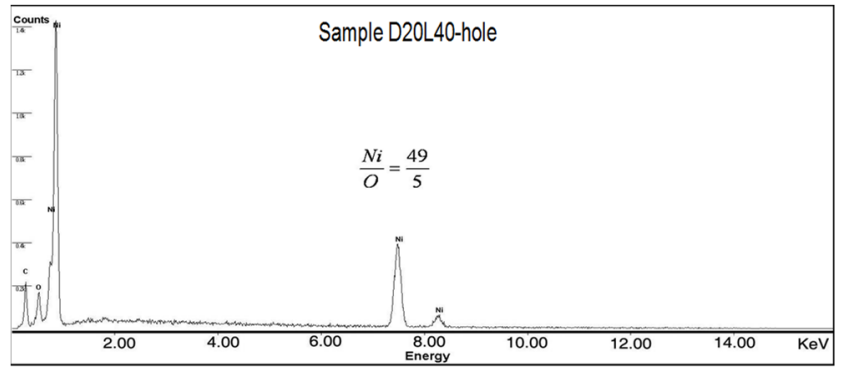

(b)

Figure 9: EDS analysis of the virgin sample D20L40 (a) surface and (b) hole.

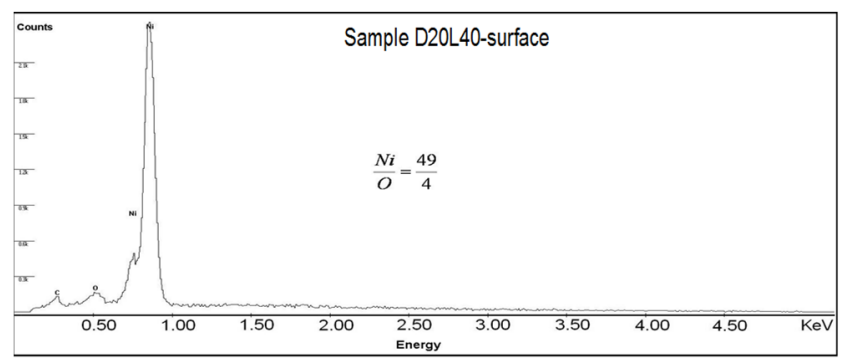

(a)

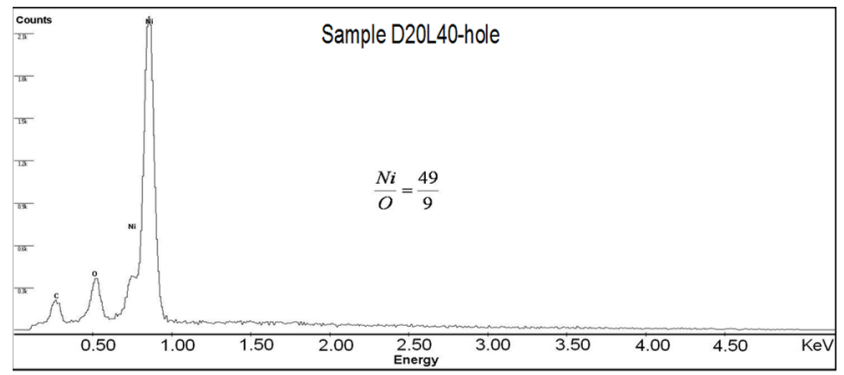

(b)

Figure 10: EDS analysis of the sample D20L40 after the corrosion test (a) surface and (b) hole. 


\section{References}

[1] Varanasi, K.K., Deng, T., Smith, J. D., Hsu, M. \& Bhate, N., Frost formation and ice adhesion on superhydrophobic surfaces. Applied Physics Letters, 97(23), 10.1063/1.3524513, 2010.

[2] Shafiei, M. \& Alpas, A.T., Nanocrystalline nickel films with lotus leaf texture for superhydrophobic and low friction surfaces. Applied Surface Science, 256, pp. 710-719, 2009.

[3] Barthlott, W. \& Neinhuis, C., Purity of the sacred lotus, or escape from contamination in biological surfaces. Planta, 202, pp. 1-8, 1997.

[4] Lee, S.J., Huang, C.H., Lai, J.J. \& Chen, Y.P., Corrosion-resistant component for PEM fuel cells. Journal of Power Sources, 131, pp. 162-168, 2004.

[5] Liu, T., Yin, Y. \& Dong, L., New application of the underwater superhydrophobic surface in the corrosion protection. Advanced Materials Research, 79-82, pp. 1115-1118, 2009.

[6] Fontana, M.G. \& Greene, N.D., Corrosion Engineering, 2nd edition, McGraw Hill, 1978. 